\title{
Applied Orientation and Interdisciplinary Integration as a Factor in Increasing Student Learning Motivation
}

\author{
Petr Nikitin ${ }^{1, *}$, Rimma Gorokhova ${ }^{1}$, Ruslan Bazhenov ${ }^{2}$, Irina Bystrenina ${ }^{3}$ \\ ${ }^{1}$ Financial University under the Government of the Russian Federation, Russia \\ ${ }^{2}$ Sholom-Aleichem Priamursky State University, Russia \\ ${ }^{3}$ Russian State Agrarian University - Moscow Timiryazev Agricultural Academy, Russia
}

Received June 19, 2020; Revised July 27, 2020; Accepted August 25, 2020

\section{Cite This Paper in the following Citation Styles}

(a): [1] Petr Nikitin, Rimma Gorokhova, Ruslan Bazhenov, Irina Bystrenina, "Applied Orientation and Interdisciplinary Integration as a Factor in Increasing Student Learning Motivation," Universal Journal of Educational Research, Vol. 8, No. 10, pp. 4931 - 4938, 2020. DOI: 10.13189/ujer.2020.081065.

(b): Petr Nikitin, Rimma Gorokhova, Ruslan Bazhenov, Irina Bystrenina (2020). Applied Orientation and Interdisciplinary Integration as a Factor in Increasing Student Learning Motivation. Universal Journal of Educational Research, 8(10), 4931 - 4938. DOI: 10.13189/ujer.2020.081065.

Copyright $\mathrm{C} 2020$ by authors, all rights reserved. Authors agree that this article remains permanently open access under the terms of the Creative Commons Attribution License 4.0 International License

\begin{abstract}
The research is devoted to the study of the process of increasing students' motivation to study physics, one of the most complex sciences of the school course. The process of increasing motivation is considered through the introduction of an optional course in high school. The research represents the organizational and methodological features of the formation of sustainable motivation of students to physics in the process of teaching the optional course "Physical Basis of Information Security", which is a program for giving theoretical knowledge about the physical foundations of information security, providing active practical work in the process of studying different ways of information security and performing laboratory work. Teaching is based on the application of the problem-based learning and active learning, as the optimal methods of searching and obtaining new knowledge. The increased level of motivation and students' knowledge is achieved through the introduction of the optional course "Physical Basis of Information Security", which includes pedagogical technologies, problem situations and practical exercises. Monitoring analysis of the results of a learning experiment proves that the experimental group, unlike the control group, has a higher level of motivation and knowledge.
\end{abstract}

Keywords Motivation, Teaching Methods, Optional Course, Teaching Physics, Problem Based Learning

\section{Introduction}

A growing number of areas for development of modern society are based on physical laws and processes, constantly developing radio engineering specialties, information technologies, information and communication systems and technologies, information security, biotechnological systems and among them [1]. The preparation of these areas places more and more demands on the knowledge of the physics course among school leavers. The results of the state final examination show low scores that students receive. This is no coincidence, since physics was and remains to be one of the most difficult subjects of school education. The attitude to physics at school is formed from the first years when students begin to study it and, unfortunately, every year there is a decrease in interest and motivation for studying it [2]. In this regard, a contradiction can be noted between the increasing requirements to the knowledge of physics and the lack of motivation for a detailed study of it.

The solution to this problem should be diverse: it can be career guidance events, clubs and optional courses, classes conducted by university professors, project activities, contests and Olympiads, etc. The possibility of an interdisciplinary optional course for increasing the motivation for studying a physics course at school should be considered. The optional course was based on questions of the applied significance of physics in life, information security issues from the point of view of physics, how 
physics and physical phenomena explain the modern achievements of our reality, for example the principle of operation of a cellular communication blocker.

\section{The Contents and Structure of the Optional Course}

Information security is fundamentally based on various processes, including physical processes occurring in channels of communication and information transmission. An optional course "Physical Basis of Information Security" was created for students in grades 10-11. This course deals with the physical basis of information leakage channels, methods, means of security and stealing information are represented from the point of view of physics $[3,4]$.

The program of the optional course is designed for 36 hours. It is planned to conduct lecture classes - 8 hours and practical classes -28 hours.

The objective of this optional course "Physical Basis of Information Security" is to review and explain the physical fundamentals of information security in plain language for high school students. Studying the course involves solving the following problems:

- to give consideration to the classification and physical basis of information leakage channels;

- to find out what means of stealing and security of information exist on each channel of information leakage;

- to consider the principle of action of the means of stealing and security of information from the point of view of physics;

- to solve tasks on each channel of information leakage.

The optional course for students is aimed at the formation of the following specific skills:

- to classify information leakage channels;

- to compare the means of stealing and security of information on each channel of information leakage;

- to describe the physical basis of information leakage channels;

- $\quad$ to describe the results of observations;

- to put forward hypotheses and draw conclusions.

One of the important problems is the problem of creating interest and increasing motivation for studying physics, preparing students for the state final examination in physics and for choosing specialties related to physical fundamentals.

A particular attention is paid to the syllabus of the optional course. The course is interdisciplinary and accumulates questions from sections of the course of physics, computer science and ICT related to the area of information security, which is very relevant and important in a modern technological society, and requires constant development and improvement [5]. The course includes issues that are based on theoretical and technological foundations from the course of physics and computer science. The course syllabus consists of the following theoretical issues of information security [6]:

Topic 1. Classification of technical channels of information leakage [7].

Topic 2. Physical basis of the acoustic channel of information leakage.

- Direct acoustic channel;

- Acoustic vibration channel;

- Acoustic-radio-electronic channel;

Topic 3. Physical basis of the electric channel of information leakage.

- Leak from electrical circuits;

- Leak on power supply circuits;

- Leak on ground circuits.

Topic 4. Physical basis of the optical channel of information leakage.

- Visual - optical channel;

- Photo-TV channel;

- Fiber optic channel.

Topic 5. Physical basis of radio channels of information leakage.

- Interception of signals from connected radio stations;

- Interception of radio signals;

- Radio beacons.

Topic 6 . The physical basis of information leakage channels due to TEMPEST.

Topic 7. Means of stealing and security of information.

- Multifunctional search device;

- Detector of hidden video cameras on an optical basis with laser illumination;

- Non-linear locator $[8,9,10]$.

A special place in the course is given to laboratory work, which examines the practical foundations of information security. Topics for seven laboratory works are listed below $[11,12]$.

Laboratory work No. 1. "Search for channels of voice information leakage."

Laboratory work No. 2. "Technical tools for detection, localization and neutralization of radio-emitting special technical devices of secret receiving information."

Laboratory work No. 3. "Technical tools for detection, localization and neutralization of special technical devices for secret receiving information using power lines of an alternative current network and lines of security (fire) alarm systems."

Laboratory work No. 4. "Search for information leakage channels using a non-linear locator. Search and discovery of radio bookmarks in the room. " 
Laboratory work No. 5. "Detection of surveillance and optical surveillance devices."

Laboratory work No. 6. "Search for information leakage channels using the field indicator. Search and discovery of radio bookmarks in the room. "

Laboratory work No. 7. "Investigation of the vibro-acoustic channel of information leakage."

The contents of the optional course are based on topics that are studied in physics classes [13, 14, 15, 16]. Studying the physical foundations of the acoustic channel of information leakage, the following topics that are studied in high school can be distinguished: "Waves", "Sound". In the section of molecular physics "Mechanical waves. Sound" the following topics are distinguished: "Wave phenomena", "Wavelength. Wave propagation velocity", "Sound waves", "Speed of sound", "Mechanical waves".

When studying the physical principles of the electric channel of information leakage, the section of physics "Electromagnetic waves" can be distinguished, which is studied in high school and includes the following topics: "Electromagnetic wave", "Radiation of electromagnetic waves", "Properties of electromagnetic waves". The concept of an electromagnetic wave begins with the consideration of the relationship between oscillating electric and oscillating magnetic fields. The Hertz doublet, which was used to obtain electromagnetic waves, is also studied.

The topics studied at high school: "Reflection of light", "Refraction of light", "Dispersion of light", "Diffraction of light" are necessary for studying an optical channel of information leakage during the classes of an optional course.

At high school, in physics classes, such topics are studied: "The principles of radio communications", "Propagation of radio waves", "Radar location". These are the topics that are necessary to understand the physical principles of radio channels of information leakage. The study of the principles of radio communication begins with the introduction of the concept of radio communication, which means "the transmission and reception of information through electromagnetic waves in a wide range - from $3^{\mathrm{x}} 10^{4}$ to $3^{\mathrm{x}} 10^{11} \mathrm{~Hz}$ [21]. Then, a radio communication scheme is studied and how information is transmitted and received is explained.

It has been proved by the analysis performed that the optional course is based on the sections of the physics course which are studied in high school.

The experimental testing of the optional course "Physical Basis of Information Security" was conducted among students in grades 10-11 of schools in the Mari El Republic.

\section{Teaching Methods}

Classes of the course are aimed at forming students' in-depth knowledge of the separate sections of physics, computer science and ICT, in particular information security issues and their physical fundamentals. It is methodologically advisable to conduct the optional course "Physical Basis of Information Security" using the problem-based learning method, which will allow getting acquainted with the various channels of information leakage, critically interpret and explain them from the point of view of physics [17].

Material in physics allows causing many problematic situations, controls the cognitive activity of students and teaches them to learn. The famous psychologist L. S. Vygotsky proved that "training will be successful only when it will not only be oriented to the level of development which is already achieved, but also run ahead a bit, presenting somewhat overstated requirements for logical thinking" [18]. It is necessary to ensure that students do not receive knowledge in a finished form, but try to acquire it on their own.

Problem-based learning is different in that the teacher creates a certain cognitive situation, helps students to highlight the problem, understand it and "accept" it; organizes students to master the new content knowledge necessary to solve the problem; offers a wide range of ways to use the obtained knowledge in practice $[19,20]$.

Thus, the application of the problem-based learning method ensures the reliability of the acquisition of knowledge, makes the learning process more meaningful and exciting, teaches to use the knowledge in practical activities, develops students' analytical and logical thinking, promotes the creative growth of the teacher, and forms the student as an active subject of learning [21].

The problem-based learning method was used during one of the classes "Communication blockers" of this optional course. Students are asked to name, for example, the Laplace formula for finding the speed of sound. And the student who will do it faster will receive an "excellent" mark. Since all the students today have phones with access to the Internet, then most likely they will want to find this information on the Internet. Meanwhile, the cellular blocker is turned on in the classroom [22, 23].

The main function of stationary jammers has become the protection from the most sophisticated listening devices (from cell phones to wireless microphones and video cameras) [24]. Another, no less important task of this device is to create a working atmosphere in company offices, to prevent distractions during meetings, negotiations, business meetings (the device blocks incoming / outgoing calls, as well as SMS messages). Stationary jammers are often used in cinemas, when showing performances in theaters, churches, mosques, temples and in many educational and prisons, that is, in places where the use of mobile phones is not desirable or even prohibited [24].

Thus, students will not be able to see the formula on the Internet. Further, in accordance with the technology of 
problem-based learning, they are asked the question: "Why do not the phones work and does not the Internet load?" Students put forward their ideas and try to explain this fact: "Perhaps there is no connection? Is a cellular blocker installed? etc.". These questions lead to the need to get the knowledge of the physical fundamentals used in such devices as communication cellular blockers. After that, the basic functions of one of such devices "Monster" are studied and the principle of its operation from the point of view of physics is explained.

The main functions of "Monster" [24]:

1. The fourteen-channel device provides a reliable protection from mobile signals, standards and radio waves;

2. The device protects only from the signals of mobile phones and does not interfere with the operation of other electronic devices;

3. The device can work stably while being turned on for a long time.

The total output power of the communication blocker is 35 watts. The device, during its operation, creates disturbance, the so-called "white noise" and, due to this, muffles the work of mobile phones and other devices that operate at the frequencies stated in the characteristics of the blocker. A device of this type ensures the disappearance of a mobile signal falling within its radius of action. The range of the jammer is up to 40 meters.

At the end of the class, students complete the task: "Find the suppressed frequencies with the "Monster" device.

Thus, after analyzing the method of problem-based learning, we can draw the following conclusions:

1. The method of problem-based learning plays an important role in learning, as it forms the thinking process, contributes to the activation of students' independent activity.

2. The application of the method of problem-based learning when studying the problems of information security from the point of view of physics allows students to gain practical knowledge and skills in the field of physics, computer science, and information security.

Laboratory works are aimed at the formation of skills of the use of equipment for the physical support of information security. Various special laboratory equipment can be used when conducting laboratory work.

The lesson examines the equipment that allows detecting hidden micro-cameras by optical sign with laser illumination, these devices work in the optical range and no radio-electronic interference or shielding can prevent them from detecting all types of hidden cameras: video cameras; camcorders with pin-hole lens; digital photo and video cameras; cameras with auto focus, which must be included in the lesson, since their use is currently relevant, because they allow the detection of hidden video cameras in various conditions: in walls, ceilings, bags, in various packages, inside an electromagnetic screen [25].
Equipment is used during search operations inside and outside the buildings, in transport, and is designed to detect special technical tools and other devices incorporating semiconductor components.

When studying such equipment, the issues of radio frequency range in various ranges, various interferences, various types of signal radiation: continuous and pulsed probing signal, signal radiation power $(1 \mathrm{~W}$ in continuous, and $15 \mathrm{~W}$ in pulse mode) are learned.

In the laboratory works, one more device is studied which is designed to carry out operational procedures to detect and localize the technical tools of secretly obtaining information, as well as to identify and control natural and artificially created channels of information leakage. These devices perform various monitoring and search tasks, such as identifying the fact of work (detection) and finding the location of radio-emitting special technical equipment that creates potentially dangerous radio emission from the point of view of information leakage; detection and finding the location of special technical tools working with radiation in the infrared range; identification of the most vulnerable places, from the point of view of the occurrence of vibro-acoustic channels of information leakage, as well as an assessment of the effectiveness of these building protection systems; identification of the most vulnerable places, from the point of view of occurrence of acoustic information leakage channels, as well as assessment of the effectiveness of room acoustic insulation [26].

It should be noted that the topics discussed in the classroom are important for gaining knowledge of the sections of the modern physics course, increasing the motivation for studying physics and, of course, getting to know the various areas of professional application of knowledge gained during physics classes. The experimental implementation of the obtained development results was aimed at testing the hypothesis of a change in students' motivation for studying physics.

By motivation, we mean "an incentive for the active work of individuals, collectives, groups, associated with the desire to satisfy certain needs." There are several types of motivation [27]:

1. Extrinsic and intrinsic motivation. Extrinsic motivation is not related to the content of a certain activity, but the circumstances which are external to the subject. Intrinsic motivation is associated not with external circumstances, but with the content of the activity itself.

2. Positive and negative motivation. Motivation based on positive incentives is called positive. Motivation based on negative incentives is called negative.

3. Stable and unstable motivation. Motivation is stable when it is based on the needs of a person, as it does not require additional reinforcement.

From the point of view of training stable positive motivation is of greatest interest, as the development of this kind of motivation is the most important component. 


\section{Results}

A pedagogical experiment on the introduction of the optional course "Physical Basis of Information Security" was conducted in high school. As a result of the experiment, the motivation for learning physics was measured. The experiment consisted of ascertaining, training, and control stages, at each of them an analysis of the students' motivation for studying physics was carried out.

Initially, two groups were identified for organizing the study: an experimental group and a control group. In the experimental group consisting of 21 students who themselves expressed a desire and signed up for the course, an optional course was held at the same time as physics classes during the first half of the school year. In the control group of 32 people an optional course was not conducted.

At the ascertaining stage of the pedagogical experiment, a questionnaire was conducted to determine the level of students' motivation for studying physics in the control and experimental groups.

10 questions were offered to be answered:

1. Do you like studying physics?

2. Is physics an interesting or a boring science?

3. Do you think physics will be useful to you in your future life?

4. Do you understand the physics study material in your textbook?

5. Are you active during physics classes?

6. What form of classes do you like most of all?

7. What is your goal in physics classes?

8. Would you like physics to be removed from the list of school subjects?

9. Do you enjoy doing homework in physics?

10. Would you like to study the physical fundamentals of information security?

Questioning results for some questions are presented in Figures 1-3. To the first question of the questionnaire: "Do you like studying physics?" 38 students, and it accounted for $72 \%$ of respondents, answered "I don't like it".

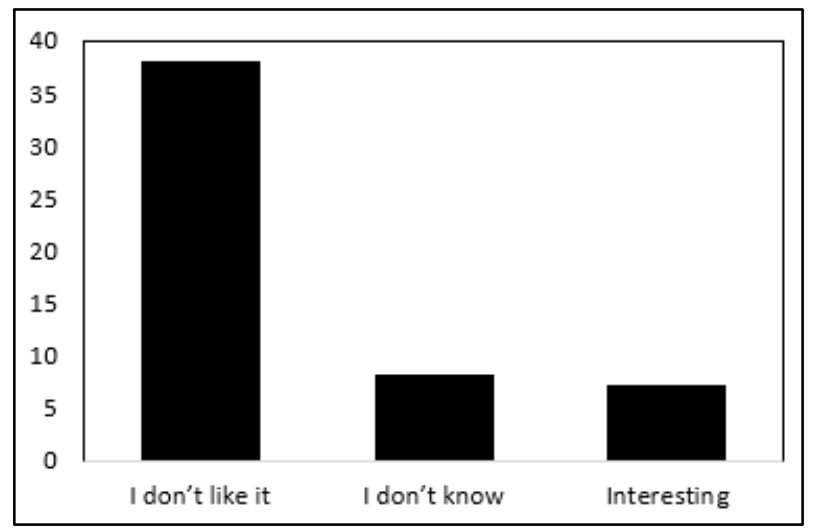

Figure 1. Distribution of results of the answer to the question: "Do you like studying physics?"
It is obvious that most of the students' answers to questions 2, 3, 8 and 9 proved the absence of motivation to study physics and only a small number of students, approximately $15 \%$, said that physics is a necessary subject. The results of answers to the question: "Do you understand the physics study material in your textbook?" are represented in Figure 2.

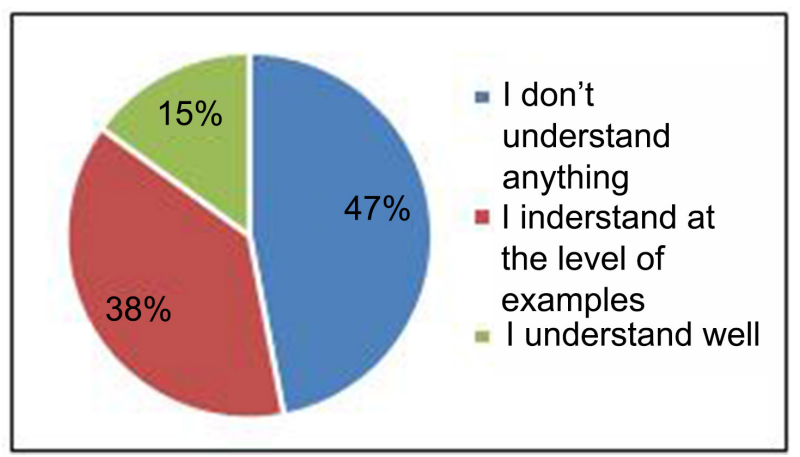

Figure 2. The results of the question: "Do you understand the physics study material in your textbook?"

To the question: "What forms of classes do you like most of all?" most of the students (76\%) answered "Laboratory work".

$77 \%$ of students expressed their desire to study the physical foundations of information security. Results of the last question: "Would you like to study the physical fundamentals of information security?" are presented in Figure 3.

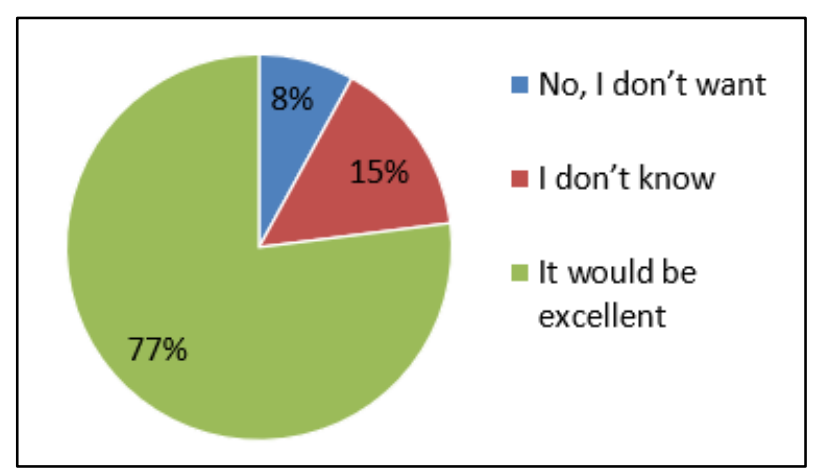

Figure 3. Results of the question "Would you like to study the physical fundamentals of information security?"

The level of motivation of students was determined according to the results of the questionnaire, - low, medium, high. An analysis of the answers of the questionnaire showed that most students (85\%) have a low and a medium level of motivation to study physics, and only $15 \%$ of students from the control and the experimental groups are ready to study physics and see its significance in their future life, in preparation for a future profession.

The analysis of the last question of the questionnaire showed that most of them would like to study the physical foundations of information security, and the school course does not provide the issues in this context. Computer 
science and ICT mainly explain the issues of cryptographic information protection.

At the training stage of the experiment, classes of the optional course "Physical Basis of Information Security" were conducted in the experimental group. Classes of the developed optional course were conducted in the 10th grade of high school during the school year. Various methods were used in the learning process, but the problem-based learning method occupied a special place there. Students put forward ideas, hypotheses, assumptions on the issues being studied, both from the section of physics, and from the section of computer science, ICT and information security.

The level of motivation in the experimental and control groups was determined at the control stage of the experiment, after conducting classes of the optional course. The survey results as a percentage of students' motivation levels before and after classes are shown in Figure 4.

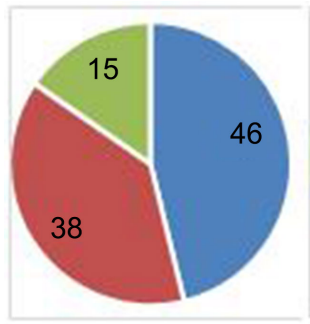

a) before the experiment

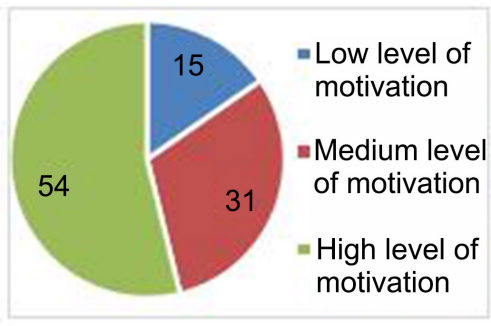

b) after the experiment
Figure 4. Levels of motivation to study physics in the experimental group

The hypothesis of the absence of a change in the level of students' motivation to study the course of physics was tested with the use of the nonparametric Wilcoxon rank sum test. The calculated value of the criterion in the experimental group and the critical value found in the table are equal, so the null hypothesis is rejected and an alternative one is accepted. The change in the results of the level of motivation in the experimental group and the observed difference in connected samples turned out to be statistically significant. Therefore, it was confirmed that conducting classes of the optional course helps to increase the motivation of students of the experimental group to study physics. Changes occurred in the control group; however, verification by the Wilcoxon rank sum test didn't confirm a statistically significant difference.

The optional course "Physical Basis of Information Security" was conducted during the school year and took place simultaneously with the study of the basic course of physics. A question that is also important and significant is the process of gaining knowledge by students. Checking changes in the level of knowledge of students was carried out on all the topics studied. The hypothesis was tested the study of topics of the optional course "Physical Basis of Information Security" and the change in the level of motivation to study physics do not affect the change in the level of knowledge of students. Testing the knowledge of this hypothesis covered primarily issues related to the topics studied during the optional course. The basic tasks were the tasks of the Unified State Exam in physics, presented in the CMM (control-and-measuring materials) specification, questions and tasks of the studied sections of the physics course, which directly or indirectly intersect with questions of the optional course. The exam tasks include, for example, such topics as the principle of superposition of electric fields, the magnetic field of a current carrying conductor, Ampere force, Lorentz force, Lentz rule (determination of direction) and others [28].

Students did control tasks in physics at the end of the school year. Assessment was performed on a 30-point scale and the results were grouped. Knowledge assessment was carried out throughout the sample, and then the level of knowledge was compared in the control and experimental groups.

The results in the control and experimental groups were grouped into intervals and are presented in Figure 5.

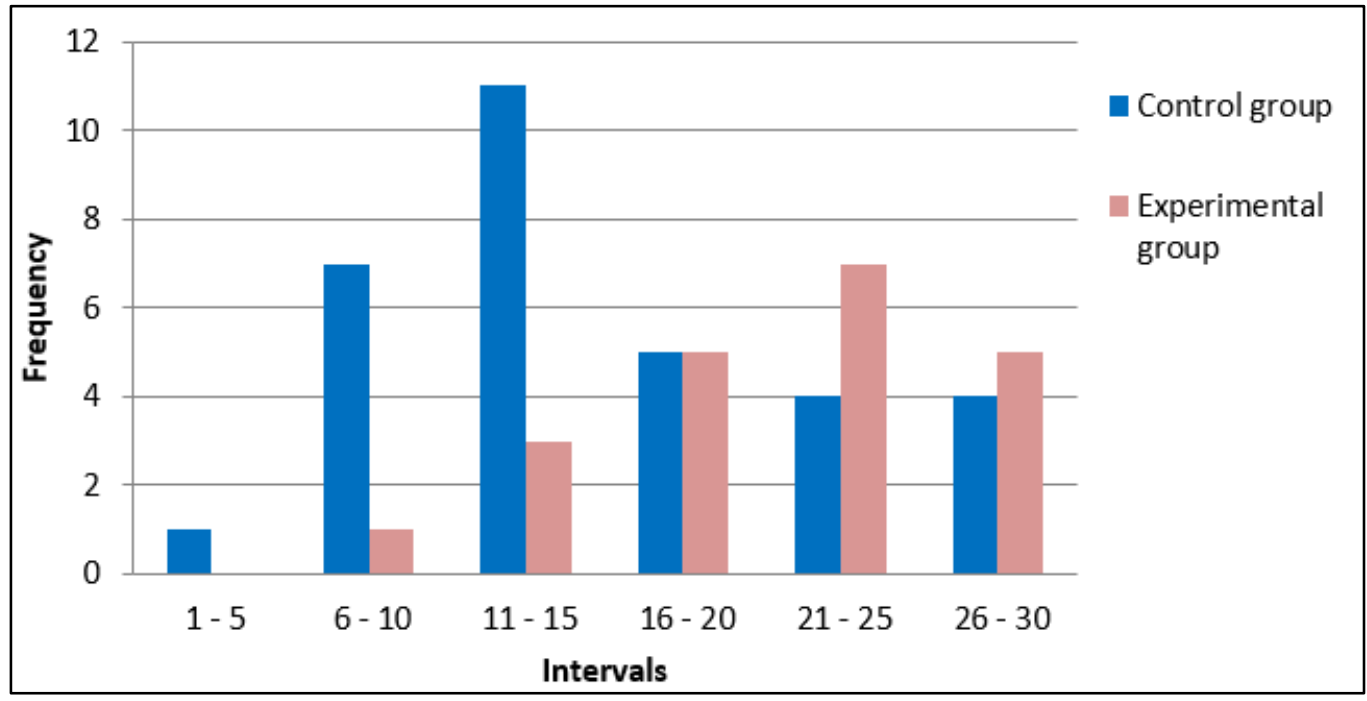

Figure 5. The distribution of the results of the control task in the control and experimental groups. 
The median value in the control group was 13,5 points, and the average value was 15,4 points, which indicates a shift in the sample to the left. In the experimental group, the median value and the average value turned out to be 22 and 21,2 , respectively, which shows the normal distribution of the sample.

The hypothesis was tested for the obtained data: the results of the control task in physics in the control and experimental groups differ statistically insignificantly. To test the hypotheses, we used Student's parametric t-test, which is used to compare the average values in independent samples corresponding to the normal distribution.

The calculation of indicators was carried out using the Two-sample t-test tool with various dispersions from the Microsoft Excel Data Analysis add-ons. The results of the calculation of the values of the indicators are listed in Table 1.

Table 1. Calculation of the Student's t-test

\begin{tabular}{|l|c|c|}
\hline Criteria & Control group & $\begin{array}{c}\text { Experimental } \\
\text { group }\end{array}$ \\
\hline Medium & 15,4 & 21,2 \\
\hline Dispersion & 45,7 & 30,2 \\
\hline t-statistics & \multicolumn{2}{|c|}{3,4} \\
\hline$t$ critical double-sided & \multicolumn{2}{|c|}{2,009} \\
\hline
\end{tabular}

The results show that the calculated value of the criterion t-statistics is 3,4 and the critical value is 2,009 , that is, $t>t_{0,05}$, therefore, it can be concluded that the null hypothesis is rejected and an alternative one is accepted: the results of the control task in physics in the control and experimental groups differ statistically significantly. This conclusion confirms that in the experimental group and the control group, the students coped with the control task not in the same way. The average and median indicators show that the result in the experimental group is higher than in the control group. Thus, the level of knowledge of students involved in the optional course was higher than in the group who did not take up this course.

\section{Conclusions}

Education solves the problems of the development of the personality and abilities of a child, his preparation for adult life. The professional self-determination of each student is very important. Knowledge of such school subject as physics is necessary for school graduates to choose their future profession in a very large number of occupations. The optional course described in the research is designed in such a way that allows students to see the connection between physics and various disciplines and to study the physical bases of information security. The study of physics together with the optional course "Physical Bases of Information Security" is aimed at increasing the level of motivation for studying physics by students and choosing their future profession.

According to the results and hypotheses obtained during the research the conclusion can be made that the study of the optional course "Physical Basis of Information Security" and the change in the level of motivation to study physics have a positive effect on the change in the level of knowledge of students.

\section{REFERENCES}

[1] M. D. Berezinskaya, A. Yu. Azarov. Information security of the modern society. Information Society: State, Problems, Perspectives, 45-52, 2017.

[2] A. V. Usova, A. A. Bobrov. Formation of learning skills at physics classes. M: Prosveshcheniye, 1988.

[3] A. A. Abidarova. Physical means of information protection. Science, Education \& Culture, No.2(36), 2019. https://cyberleninka.ru/article/n/fizicheskie-sredstva-zaschit $\mathrm{y}$-informatsii

[4] G. A. Markov. Questions of physical safety of information. Questions of Cyber Safety, No.4(12), 2015, https://cyberleninka.ru/article/n/voprosy-fizicheskoy-bezop asnosti-informatsii.

[5] V. M. Kirillov, A. N. Sobolev, A. V. Kiselyov. Physical foundations of perspective of computing technology and providing information safety, Gelios ARV, Moscow, 2012.

[6] A. A. Malyuk. Principles of formation of the theory of information protection. Safety of Information Technologies, No.18 (2), 5-9. 2011.

[7] T. D. Baboshina. Analyses of means and methods of information protection. Modern Research Bulletin, No.6.1(21), 326-327, 2018.

[8] A. N. Sobolev, V. M. Kirillov. Physical foundations of technical devices for IT security support, Gelios ARV, Moscow, 2004.

[9] V. A. Vorona, O. V. Kostenko. Means and tools of information leakage protection through technical channels. Comp. Nanotechnol, No.3, 208-223, 2016.

[10] I. I. Khaiitova. Methods and means of providing security. Young Scientist, No.4(138), 187-188, 2017, https://moluch.ru/archive/138/38796/.

[11] A. A. Tyurina. Technical channels of information leakage. Theory and Practice of Modern Science, No.5(23), 1102-1105, 2017.

[12] O. S. Avsentyev, V. V. Menshikh, A. O. Avsetyev. Model of optimization of the process of transmitting information through communication channels in the conditions of threats to its security. Telecommunications, No.1, 28-32, 2016.

[13] V. A. Kasyanov. Physics. 10 $0^{\text {th }}$ grade. Major level. A textbook for secondary schools, Drofa, Moscow, 2013.

[14] V. A. Kasyanov. Physics. $11^{\text {th }}$ grade. Major level. A 
textbook for secondary schools, Drofa, Moscow, 2011.

[15] G. Ya. Myakishev, A. Z. Sinyakov. Physics. Oscillations and waves. $11^{\text {th }}$ grade. Major level. A textbook for secondary schools, Drofa, Moscow, 2010.

[16] G. Ya. Myakishev, A. Z. Sinyakov. Physics: Optics. The Quantum Physics. $11^{\text {th }}$ grade. A textbook for in-depth study of physics, Drofa, Moscow, 2002.

[17] D. V. Vilkeev. Cognitive activity of students within the problematic nature of teaching the basics of science at school. Kazan, 1967.

[18] L. S. Vygotsky. Pedagogical psychology. Pedagogika-Press, Moscow, 1996.

[19] V. Okon. Foundations of problem-based education. Prosveshcheniye, Moscow, 1968.

[20] L. A. Levitskiy. To the application of problem-based learning in the educational process in mathematics. Actual Problems of Military Scientific Research, No.6 (7), 410-413, 2020.

[21] L. G. Kulikova, M. P. Tyrina, A. Pardala. Problem-based learning as a way of solution of pedagogical problems. Problems of Modern Pedagogical Education, No.65(2), 180-184, 2019.

[22] A. L. Karpuk. Problem based learning of physics in the process of solving problems. Physics: Problem Based Learning, No.1, 21-29, 2002.

[23] M. I. Semina. From the experience in the technology of problem-based education during physics classes. Experiment and Innovations at School, 5, 2012, https://cyberleninka.ru/article/n/iz-opyta-raboty-po-tehnolo gii-problemnogo-obucheniya-na-urokah-fiziki.

[24] O. A. Chizhykov. Cognitive activity of students in physics lessons. Municipal Education: Innovation and Experiment, No.5, 63-70, 2015, https://cyberleninka.ru/article/n/poznava telnaya-aktivnost-uchaschihsya-na-urokah-fiziki.

[25] Cell phone jammer "Monster 16CH". New Systems of Security: online shop, http://www.n-sb.ru/podavitel-sotovoi -svyazi-monster-16ch.php.

[26] T. V. Panchenko, M. H. Lashkina, Yu. Nesteriak. Public request for information security. Public Management, No.2(22), 116-129, 2020.

[27] V. E. Mitrokhin, A. V. Zhabina. The laws of propagation of light rays in optical guide systems. Laboratory Guidelines. Ministry of Transport of the Russian Federation, Federal Agency for Railway Transport, Omsk State Transport University. Omsk, 2011.

[28] Yu. N. Bogdanov. Staff motivation: textbook. INFRA, Moscow, 2006. 